\title{
The Bioavailability of Circulating Antibody-Bound Insulin Following Insulin Withdrawal in Type I (Insulin-Dependent) Diabetes
}

\author{
N. J. A. Vaughan, J. A. Matthews, A. B. Kurtz and J. D. N. Nabarro \\ The Cobbold Laboratories, The Middlesex Hospital, London, UK
}

Summary. Insulin withdrawal studies were performed in 12 Type 1 (insulin-dependent) C-peptide negative diabetic patients with low to moderate insulin antibody levels, to assess the biological availability of antibody-bound insulin and its clinical significance. There was a highly significant correlation between the extent to which the free insulin concentration was maintained during the period of insulin withdrawal and both the level of insulin-binding by serum and the total insulin concentration at the start of the study. During insulin withdrawal, the patients who best maintained their cir- culating free insulin levels showed the smallest increases in blood glucose and 3-hydroxybutyrate concentrations. We conclude that antibody-bound insulin is available for physiological action, and that in those individuals with moderate antibody concentrations it is capable, in the fasting state, of maintaining free insulin levels. In these circumstances insulin antibodies are behaving as simple carrier proteins.

Key words: Type 1 diabetes, insulin, insulin antibody, pharmacokinetics.
Most clinical studies concerning insulin antibodies have been directed towards the deleterious effects, such as insulin resistance, which are associated with very high antibody levels [1]. Little is known about the effect of the more modest levels of antibodies that exist in most Type 1 (insulin-dependent) diabetic patients. In these patients, it is evident from measurement of antibody-bound insulin that substantial quantities of insulin may be present in the plasma and it has been suggested that this source of insulin could act as a buffer to fluctuations in insulin levels [2].

A correlation between the level of insulin binding by serum and diabetic control as judged by the haemoglobin $\mathbf{A}_{1}$ percentage has been demonstrated in C-peptide negative patients on a once-daily insulin regimen [3], but this association was not observed when the patients were changed to a twice-daily insulin regimen. The problem of whether antibody-bound insulin is available for biological action, and the extent to which it might be clinically useful, is of particular interest because over recent years there has been a reduction in both the prevalence of insulin antibodies and the insulin-binding levels found in those who do form antibodies. This is a consequence of the increased purity of insulin preparations and the increase in the use of porcine insulin. To assess the availability of insulin from the antibodybound pool, we performed studies on Type 1 diabetic patients who had low to moderate serum insulin binding and no residual C-peptide secretion. After careful depletion of subcutaneous insulin, subjects were stabilised on intravenous insulin which was then discontinued. The only source of free insulin would then be from the pool of insulin bound to antibody. The concentrations of free and total insulin in serum and of glucose and 3-hydroxybutyrate in blood were measured to assess the bioavailability of this source of insulin.

\section{Subjects and Methods}

\section{Subjects}

The twelve Type 1 diabetic patients studied were aged 28-56 years (mean 44 years), with duration of disease 8-40 years (mean 19 years). They were within $10 \%$ of ideal body weight. All were receiving twicedaily mixtures of short and intermediate acting highly purified porcine insulins before the study. Their usual insulin requirements were less than $1 \mathrm{U} / \mathrm{kg}$ daily and there had been no episodes of ketoacidosis in the year before the study. The absence of endogenous insulin secretion was established by finding no detectable C-peptide in serum either before or $6 \mathrm{~min}$ after an intravenous injection of glucagon $1 \mathrm{mg}$ [4]. All subjects gave their informed consent to the study which had received Ethical Committee approval.

To determine the relationship between insulin binding and the total insulin concentration in serum, samples from 95 Type 1 diabetic patients were selected to cover a range of insulin binding and were assayed for total insulin concentration. Some were treated with bovine 

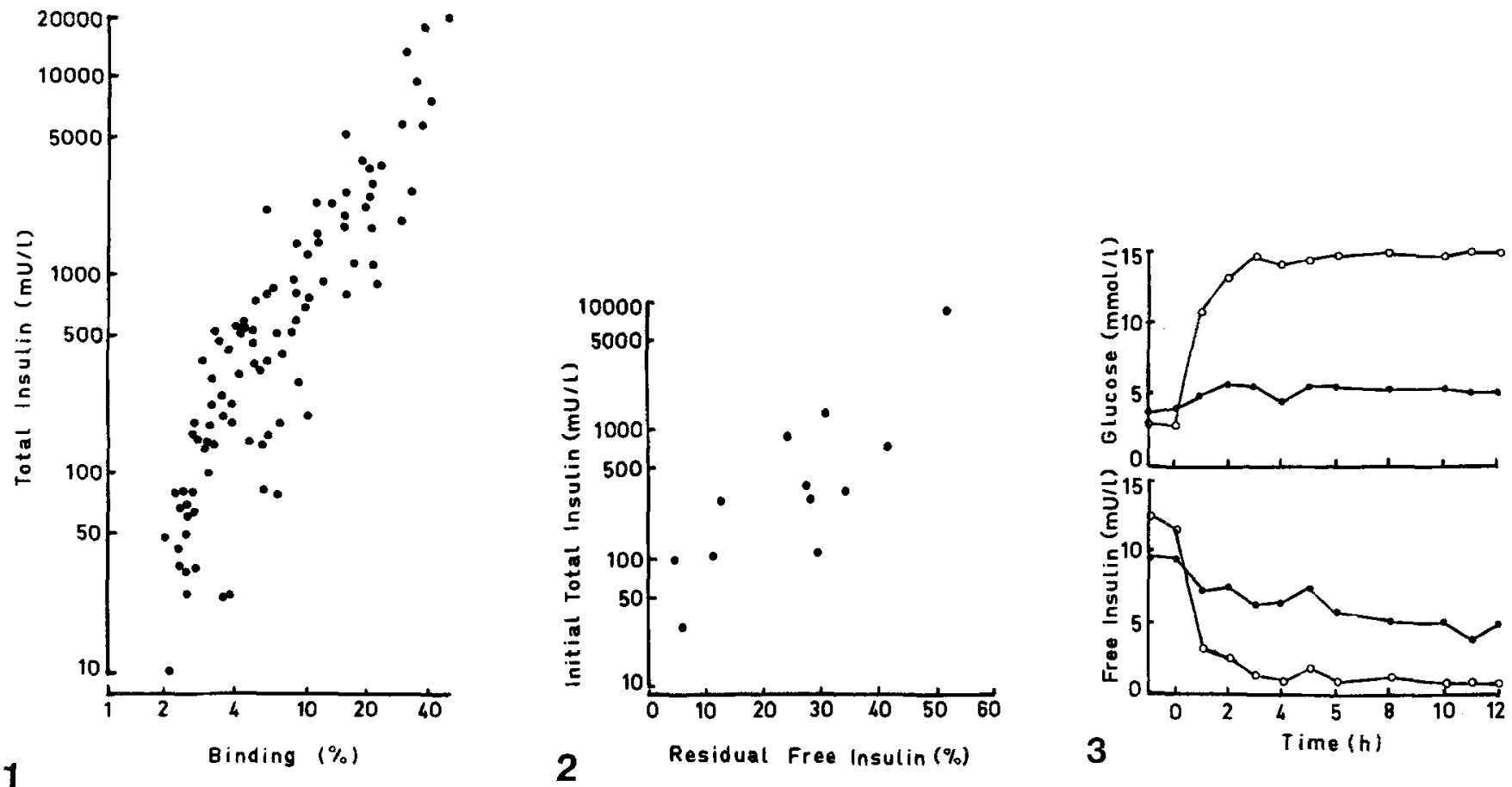

Fig. 1. The total concentration of insulin in serum plotted against the percentage binding of labelled porcine insulin for 95 selected sera. Both scales are logarithmic

Fig. 2. The total concentration of insulin in serum at the start of the insulin withdrawal study plotted on a logarithmic scale against the free insulin concentration at the end of the study (expressed as a percentage of the free insulin concentration at the start of the study). Twelve subjects were studied (they are not included in Figure 1)

Fig. 3. The concentrations of free insulin in serum and of glucose in blood during $12 \mathrm{~h}$ insulin withdrawal in two subjects, one without ( $\mathrm{O}-\mathrm{O})$ and one with insulin-binding antibodies (

insulin and some with porcine insulin; all had, in the past, been treated with conventional bovine insulins.

\section{Experimental Protocol}

Patients were admitted to a metabolic ward during the morning of the day before the study. They had been instructed to take only short-acting insulin the previous night and to come to the ward fasting and without taking any further insulin that morning. An intravenous cannula was inserted into one arm and an infusion of porcine insulin commenced. A further cannula was inserted in the opposite arm for blood sampling. They continued with their normal diet and normoglycaemia was maintained by making appropriate adjustments to the insulin infusion rate. All subjects were fasted from $22.00 \mathrm{~h}$ until the end of the study; insulin requirements overnight varied from $0.5-2.0 \mathrm{U} / \mathrm{h}$ in different individuals (mean $1.0 \mathrm{U} / \mathrm{h}$ ). At $07.00 \mathrm{~h}$ the following morning, after a basal blood sample had been drawn, the insulin infusion was discontinued. The binding of labelled insulin was determined on the basal sample. Further blood samples, for the measurement of free insulin, total insulin, glucose and 3-hydroxybutyrate concentrations, were taken at hourly intervals (except at 14.00 and $16.00 \mathrm{~h}$ ) for $12 \mathrm{~h}$. The study was ended by an intravenous injection of porcine insulin, a meal and a modified dose of their usual subcutaneous insulin.

\section{Assay Methods}

Free and total insulin concentrations in serum were determined using the method of Nakagawa et al. [5]. The binding of ${ }^{125}$ I-labelled insulin by serum was determined using a polyethylene glycol separation procedure [6]. The mean $\pm S D$ non-specific binding (i. e. binding of insulin by sera from normal individuals) was $1.4 \pm 0.2 \%$; this has not been subtracted from the results. The C-peptide concentration in plasma was measured as described by Heding et al. [7] with modifications suggested by Kuzuya et al. [8]; aprotinin $100 \mathrm{U} / \mathrm{ml}$ blood was used to prevent proteolytic degradation. The detection limit was $30 \mathrm{pmol} / 1$. Plasma glucose was measured by a glucose oxidase method using a Beckman glucose analyser. Plasma 3-hydroxybutyrate was estimated by standard enzymatic analysis [9].

\section{Statistical Methods}

Results were analysed using Spearman's rank correlation test.

\section{Results}

Figure 1 shows the relation of the total insulin concentration to the binding of labelled insulin for sera from 95 Type 1 diabetic patients, whose sera bound $2 \%-40 \%$ of labelled insulin, and illustrates that even with quite modest antibody levels the plasma can contain large amounts of insulin. Sera from the 12 subjects studied bound $1.2 \%-39 \%$ of labelled insulin (mean $6.8 \%$ ).

Table 1 shows the results obtained in the insulin withdrawal study. The subjects whose sera had the 
Table 1. Serum concentrations of total and free insulin, glucose and 3-hydroxybutyrate at the start of the study and after $12 \mathrm{~h}$ withdrawal of insulin

\begin{tabular}{lll}
\hline & Initial & Final \\
\hline Total insulin $(\mathrm{mU} / 1)$ & $30-8470(318)$ & $13-6360(214)$ \\
Free insulin $(\mathrm{mU} / 1)$ & $9.1-73(23.7)$ & $0.5-16(5.1)$ \\
Glucose $(\mathrm{mmol} / \mathrm{l})$ & $3.0-8.1(5.3)$ & $5.1-20.6(15.5)$ \\
3-Hydroxybutyrate & $0.06-0.32(0.18)$ & $0.59-4.01(2.77)$ \\
(mmol/1) & & \\
\hline
\end{tabular}

Results in 12 subjects given as range with the median in parentheses

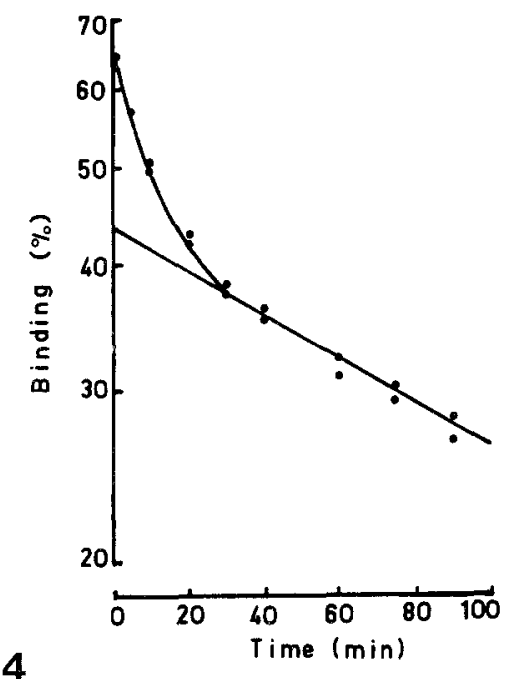

Fig.4. The dissociation of bound labelled porcine insulin in vitro from serum from the subject shown in Figure $3(-)$; the percentage binding of labelled insulin on a logarithmic scale is plotted against time. The experiment was performed at $37^{\circ} \mathrm{C}$ and at time 0 an excess of unlabelled insulin was added. The half-life of dissociation of the slowest component, indicated by the straight line, is $140 \mathrm{~min}$

highest insulin binding maintained their free insulin concentrations best during insulin withdrawal $(r=0.88$, $p<0.01$ ); and as shown in Figure 2 those with the highest total insulin concentration in serum also maintained their free insulin best $(r=0.80, p<0.05)$. Maintenance of the free insulin concentration was associated with the least metabolic deterioration as judged by the rise in blood glucose $(r=-0.76, p<0.05)$ and 3-hydroxybutyrate $(r=-0.68, p<0.05)$.

To illustrate this further, the individual studies on two subjects are shown in Figure 3; one had the highest antibody level (39\% insulin-binding; initial total insulin $8,470 \mathrm{mU} / 1)$ and one the lowest $(1.2 \%$ insulin-binding i.e. no detectable antibodies; initial total insulin $30 \mathrm{mU} / 1$ ). In the patient without antibodies, there was a rapid fall in the free insulin concentration to negligible levels after $4 \mathrm{~h}$. In contrast, the antibody-positive subject showed only a slow decline in the free insulin concentration and at the end of $12 \mathrm{~h}$ still had a level that was $52 \%$ of the initial concentration. The antibodynegative patient experienced a rapid rise in plasma glucose and 3-hydroxybutyrate concentrations and was clinically ketotic after $12 \mathrm{~h}$ of insulin deprivation (blood glucose: $15.6 \mathrm{mmol} / \mathrm{l}$; 3-hydroxybutyrate: $4.0 \mathrm{mmol} / \mathrm{l}$ ). In marked contrast, the antibody-positive subject still had a near normal plasma glucose concentration at $12 \mathrm{~h}$ $(5.1 \mathrm{mmol} / 1)$. The rise in 3-hydroxybutyrate was likewise small $(0.5 \mathrm{mmol} / 1$; final concentration $0.59 \mathrm{mmol} /$ 1). In the antibody-positive subject the total insulin concentration showed a slow decline over the $12 \mathrm{~h}$ of insulin withdrawal from an initial value of 8,470 to $6,360 \mathrm{mU} / 1$; this gave a half-life for the clearance of insulin from the circulation of $21 \mathrm{~h}$. In this subject the dissociation rate of insulin from antibody was studied in vitro (Figure 4); the slowest component, which represents the highest affinity antibodies, had a half-life of dissociation of $140 \mathrm{~min}$, considerably less than the halflife of insulin clearance from the circulation.

\section{Discussion}

Large amounts of insulin can circulate bound to antibody. As IgG is distributed throughout the extracellular fluid [10,11], amounts of bound insulin in the range $20-100 \mathrm{U}$ can occur in insulin-treated patients with moderate antibody titres. Such large quantities of insulin must have a biological effect, provided that bound insulin dissociates in vivo; dissociation is easily demonstrated in vitro [12]. The release of antibody-bound insulin at inappropriate times has been implicated as a cause of hypoglycaemia [13].

In this study we have shown that antibody-bound insulin is effective in maintaining circulating free insulin when the usual sources of insulin, depots at injection site and endogenous secretion, are excluded.

If the clearance of insulin proceeds entirely via free insulin then the antibody may act as a simple binding protein or buffer without any long-term effect on insulin dose requirements - a situation analogous to the binding of thyroxine by thyroxine-binding globulin (high affinity), pre-albumin and albumin (low affinity) in the circulation. Such a concept would not hold at extremes of antibody concentration. When very high levels of insulin-binding antibody are associated with insulin resistance, it is possible that insulin antibody complexes are removed from the circulation by macrophages. With low levels of antibody, and only small amounts of bound insulin, the dissociation of insulin from the antibody becomes rate limiting because the amount of insulin delivered into the free insulin pool equals the dissociation rate constant multiplied by the amount of bound insulin: during insulin withdrawal the insulin will be 'stripped' from the antibody leaving residual insulin on the most slowly dissociating antibodies and resulting in a rapid fall in the free insulin concentration. The potential clinical advantage of insulin availability from the antibody bound pool which we have demonstrated during insulin withdrawal may well be of significance and is most likely to benefit patients 
on once-daily insulin regimens [3]. However, the effectiveness of some of the newer methods of insulin administration, such as continuous subcutaneous infusion, might well be impaired by insulin antibodies, which would be expected to damp down and prolong the meal-time peaks of insulin concentration produced by this technique [14].

With increasing use of insulins of lower immunogenicity than conventional bovine insulin preparations, the occurrence in patients of clinically significant antibody titres will become less usual.

Acknowledgements. N.J.A.V. was supported by a Research Training Fellowship from the Medical Research Council and J.A. M. was supported by a grant from Nordisk Insulin. We would also like to thank the Special Trustees of The Middlesex Hospital for essential facilities.

\section{References}

1. Kurtz AB, Nabarro JDN (1980) Circulating insulin-binding antibodies. Diabetologia 19:329-334

2. Dixon K, Exon PD, Malins JM (1975) Insulin antibodies and the control of diabetes. Quart J Med 44: 543-553

3. Gray RS, Borsey DQ, Kurtz A, Rainbow S, Smith AF, Elton RA, Duncan LJP, Clarke BF (1981) Relationship of glycosylated haemoglobin to C-peptide secretory status and antibody binding of insulin in insulin-dependent diabetes. Horm Metab Res 13: 599-603

4. Faber OK, Binder C (1977) B-cell function and blood glucose control in insulin dependent diabetics within the first month of insulin treatment. Diabetologia 13: 263-268

5. Nakagawa S, Nakayama H, Sasaki T, Yoshino K, Yu YY, Shino- zaki K, Aoki S, Mashimo K (1973) A simple method for the determination of serum free insulin levels in insulin-treated patients. Diabetes 22: 590-600

6. Kurtz AB, Matthews JA, Mustaffa BE, Daggett PR, Nabarro JDN (1980) Decrease of antibodies to insulin, proinsulin and contaminating hormones after changing treatment from conventional beef to purified pork insulin. Diabetologia 18: 147-150

7. Heding LG, Munkgaard Rasmussen S (1975) Human C-peptide in normal and diabetic subjects. Diabetologia 11:201-206

8. Kuzuya H, Blix PM, Horwitz DL, Steiner DR, Rubenstein AH (1977) Determination of free and total insulin and C-peptide in insulin treated diabetics. Diabetes 26: 22-29

9. Gibbard S, Watkins PJ (1968) A micro-method for the enzymatic determination of D- $\beta$-hydroxybutyrate and acetoacetate. Clin Chim Acta 19: 511-521

10. Andersen SB (1964) Metabolism of human gamma globulin. Blackwell Scientific Publications, Oxford

11. Kruse V (1981) Effect of insulin-binding antibodies on free insulin in plasma and tissue after subcutaneous injection. A model study. In: Keck K, Erb P (ed) Basic and clinical aspects of immunity to insulin. de Gruyter Berlin, New York, pp 319-334

12. Kurtz AB, Matthews JA, Nabarro JDN (1978) Insulin-binding antibody: reaction differences with bovine and porcine insulins. Diabetologia 15: 19-22

13. Harwood R (1969) Insulin-binding antibodies and 'spontaneous' hypoglycaemia. N Engl J Med 262:978-979

14. Nabarro JDN, Mustaffa BE, Morris DV, Walport MJ, Kurtz AB (1979) Insulin deficient diabetes. Diabetologia 16: 5-12

Received: 30 June 1982

and in revised form: 21 February 1983

Dr. A. B. Kurtz

The Cobbold Laboratories

The Middlesex Hospital

London W1N 8AA, UK 